\title{
Esta paisagem é surrealista
}

LyARA Apostólico Universidade de São Paulo/ECA-USP 


\section{Resumo}

O objetivo deste artigo é demonstrar, através de exemplos tomados de algumas metrópoles contemporâneas, que a organização e a leitura do espaço e das mensagens nestas cidades aproxima-se muito de diversos efeitos e rupturas expressivas buscados pelo surrealismo.

Palavras-chave

espaço, cidade, rupturas expressivas

\section{Abstract}

The objective of this article is to demonstrate, through examples taken from some contemporary metropolises, that the organization and the reading of the space and of the messages in these cities, approaches a lot to several effects and expressive ruptures desired by surrealism.

Key words

space, city, expressive ruptures 
"Śe nunca atentou nisso, é porque vivemos, de modó incorrigivel, distraidos das coisas mais importantes. ". Guimarães Rosa

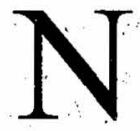
ão. Não vou falar de uma imagem de Man Ray nem de uma pintura de.Dali. A paisagem a que me refiro é esta! Esta que vemos da janela do carro ou quando caminhamos pelas ruas de uma metrópole, qualquer metrópole, ou pelo menos, todas as metrópoles ocidentais, com seus arranha-céus vitrificados e sua publicidade caótica.

Esta paisagem, que inocentemente nos circunda e tenta nos convencer de que tem suas raízes profundamente estabelecidas no mais fértil solo da razão, é mais surrealista do que qualquer trabalho que um artista surrealista poderia jamais imaginar:

Mas como chegamos a este paradoxo absurdo, no qual o resultado das mais modernas tecnologias de materiaisse de construção, fruto de pesquisas exaustivas de cientistas de formação positivista, terminou por constituir uma paisagem onde o sonho,e a imaginação encontram sua mais pavimentada rodovia?

Não há como descartar em Descartes a semente do sonho plantada $\div$ e quase sepultada - sob a palavra pensar porque, ao contrário do que se fez acreditar, ."penso, logo existo" equivale a "imagino, logo existo" pois que pensar em Descartes sempre teve um sentido amplo:

uma coisa que pensa diz, é uma coisa que duvida, entende; concebe, afirma, nega, deseja, imagina e sente; pois sentir, como ocorre nos sonhos, é uma forma de pensar. Posto que o pensamento é a essência da menté, a 
mente tem que pensar sempre, inclusive durante o sono profundo. (Russell, 1947)

Que dizer também da intuição? Não é ela o elemento fundamental sem o qual não há liga na argamassa de qualquer ciência?

Todo mundo lembrar-se-á que a intuição lógica e pura, que a intuição pura, repito, boa para toda obra, dentro das casas particulares de ciências também particulares, carregava, de há muito, no seu ventre, um filho ilegitimo que nada mais era senão o da própria fisica e que esse filho, na época de Maxwall e de Faraday, pesava já, sensivelmente, com essa persuasão não equívoca e com essa força da gravidade pessoal que não deixava lugar a nenhuma dúvida quanto á paternidade Newtoniana da criança. (Dali, 1974)

A engenharia moderna é este filho, donde se conclui, facilmente, que a cidade, a grande metrópole contemporânea é a dileta neta da mais pura intuição.

A estrutura da cidade não é senão o próprio reflexo da estrutura do Homem. E como poderia ser diferente, já que criadores e criaturas estão inseparavelmente atados pelas regras da semelhança?

As cidades, à medida em que crescem e passam de pequenos vilarejos a grandes conglomerados de prédios e de gente, vão, aos poucos, tentando domar o caótico ímpeto inicial através de leis, regimentos, estatutos e códigos de trânsito.

O Homem faz o mesmo. O veloz cavalo alado da imaginação infantil vai, aos poucos, perdendo as penas de suas asas e termina, gordo e reumático, puxando a pesada carroça da vida cotidiana real e lógica.

Mas o Homem, como disse Breton, é um "sonhador definitivo" e a água empoçada da imaginação sempre se infiltra por frestas minúsculas e imperceptíveis até que começa a pingar aqui e ali.

E essas infiltrações estão por toda a cidade. Água pinga por todo lado! 


\section{O caos visual da cidade}

A publicidade é, sem dúvida, o exato lugar onde a imaginação recebeu salvo-conduto no mundo contemporâneo. Podemos dizer, com Breton, que "aquela imaginação que não reconhecia limites, agora só se lhe permite funcionar de acordo com as leis de uma utilidade arbitrária", e a publicidade é uma destas utilidades.

É bem verdade que, em muitas peças publicitárias de revista, outdoors ou televisão, podem-se reconhecer fortes traços das rupturas expressivas características do surrealismo; mas o observador desavisado deve atentar para as diferenças entre o pé e a pegada, pois o que esta tem de vestígio, aquele tem de peso material que pisa "no que a vida tem de mais precário, vale dizer, na vida real" (Breton, 2001).

Não me interessa aqui, portanto, analisar o conteúdo e a forma de certas mensagens publicitárias, por mais criativas e inusitadas que sejam. Ao contrário, o que me chama a atenção é um fenômeno involuntário e que não é passível de projeto, isto é, ocorre sem que os envolvidos consigam exercer sobre ele nenhum tipo de controle.

Trata-se, precisamente, do fenômeno que ocorre na imagem ao lado.

Aqui, a odisséia de nosso Ulises é concorrer ao governo do estado mexicano de Oaxaca e, em seu

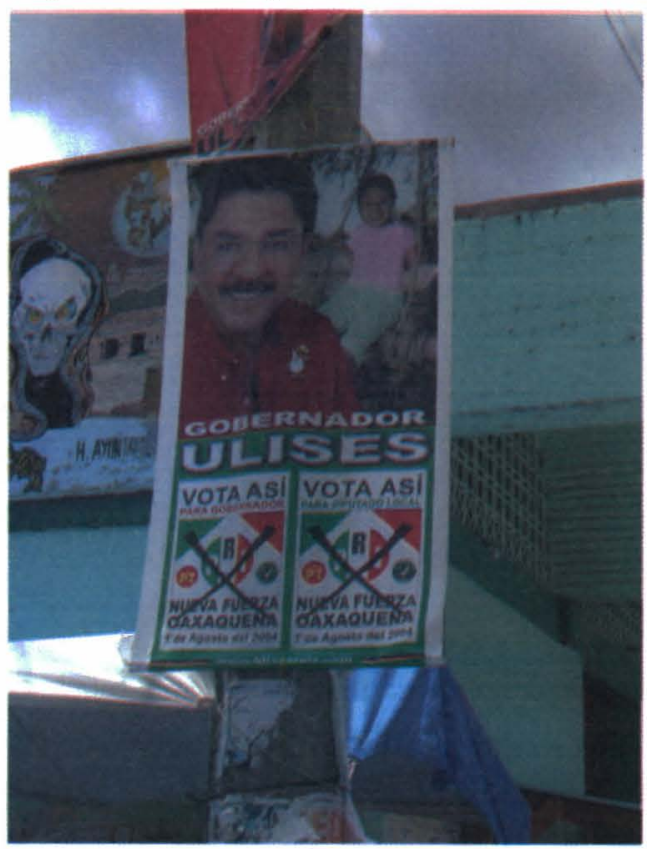


banner publicitário,vemo-lo sorridente, tendo, ao seu lado esquerdo, uma também sorridente menina. A velha fórmula candidato + criança + sorriso $=$ votos encontra, nesta peça gráfica, sua expressão mais óbvia e não seria digna de nota não fosse um terceiro sorriso, sinistro e desafiador, que se impõe à percepção do (e)leitor.

Os criadores do banner optaram por colocar a infância, passado de todos nós, ao lado esquerdo de Ulises e quis o fortuito acaso que, de seu lado direito, figurasse o futuro inexorável de todos nós. Lá está Ulises agora, no breve intervalo entre o nascimento e a morte expondo a todos nós a insignificância e efemeridade da condição humana. A mensagem agora não é mais sobre uma eleição casual e corriqueira e o outrora candidato perde sua cidadania mexicana para transformar-se no epíteto do Homem.

Ulises agora é Hamlet diante do crânio de Yorick, o bobo da corte que o divertia quando criança...

Alexandre morreu, Alexandre foi enterrado, Alexandre reverteu ao pó, o pó à terra, da terra se faz a argamassa. E porque com essa argamassa, na qual ele se transformou, não podem tapar um barrio de cerveja?

Não menos shakesperiano é o itinerário percorrido por Peñuela em sua arqueologia da palavra mesopotâmica "lugal": do cajado do pastor à sua representação gráfica, à representação do cajado na mão de um homem, este conjunto passando a representar homem grande, que, finalmente, significa o conceito de rei cuja escrita cuneiforme em nada lembra, nem cajado nem rei.

Do cajado ao signo de rei, de Alexandre à cerveja, de Ulișes ao destino da humanidade. Que corrente é esta cujos elos invisíveis se atam, de maneira tão estreita, unindo duas coisas que, de outra forma, seriam antípodas? Como seguir este fio de Teseu que nos levará à saída do labirinto?

É Peñuela quem sugere: 
formado pela percepção racional e rasteira a que estamos, infelizmente, acostumados.

Somente isto já bastaria para que o método crítico-paranóico fosse ensinado em todas as escolas primárias e secundárias... Mas olhemos a cidade!

O caos visual no qual apelos comerciais se mesclam à sinalização de trânsito, nomes de lojas e faixas de divulgação disto ou daquilo resultam em uma paisagem-colagem composta de textos, imagens e cores.

Esse agrupamento de coisas e assuntos os mais díspares possiveis é o mais rico ambiente para o surgimento dos acasosobjetivos. Ferdinand Alquié define assim o acaso-objetivo:

Trata-se sempre, de um encontro que, objetivamente, ocorre ao acaso e que, de fato, parece não ter sido um acaso, isto é, parece significar alguma coisa. (trecho de fragmento citado por Peñuela, 1986)

Essa colagem urbana, casual e coletiva sussurra, insistentemente, um discurso oculto. Discurso este de uma "irracionalidade concreta" e ancestral que entra, furtivamente, despistando os sentinelas da razão para alojar-se no canto mais recôndito da mente, onde espera, pacientemente, a hora de tornar-se sonho.

O método crítico-paranóico de Dali funciona como um "líquido revelador" que permite que este discurso não tenha que esperar até a hora do sono para revelar-se, mas que possa ser interpretado e assimilado no instante mesmo em que é percebido.

Mas em que, exatamente, consiste o método?

\section{Fenômeno da analogia}

Os surrealistas conheciam muito bem o poder desse mecanismo para a criação de suas obras. É Reverdy quem o batiza de fenômeno da analogia, que para ele funciona "aproximando sem comparação realidades remotas cujo motivo de relacionamento somente o espírito foi capaz de apreender". 
Devo ir, portanto, de vestigio em vestigio, juntar algo daquilo que outros recolheram em suas longas caminhadas pelo mar dos signos, associar traços de culturas diferentes e me preparar para os sobressaltos da surpresa. Em suma, tenho que navegar à deriva, enfrentar as fatalidades da aventura sem, contudo, perder a esperança de que essa aventura me arraste até os confins do acaso objetivo.

Muito familiar nos parece este fio misterioso que tece, com sua lógica própria, as imagens dos sonhos. Mas o que dizer dos exemplos acima, visto que não dormiam aqueles que os propuseram na hora em que os propunham?

Estamos falando, nesses casos, de um "delírio da associação interpretativa, comportando uma estrutura sistemática", fenômeno este característico da paranóia. Mas este delírio não é loucura pura e simples, pois que está submetido a uma atividade crítica constituindo o que Dali denominou atividade crítico-paranóica.

Dali define assim a atividade crítico-paranóica:

método espontâneo de conhecimento irracional baseado na associação crítico-interpretativa dos fenômenos delirantes. (...) A atividade critico-paranóica é uma força organizadora produtiva de acasos objetivos. (...) atitude ativa, sistemática, organizadora, cognoscitiva, desses mesmos fenômenos (irracionais), considerados como fenômenos associativos, parciais e significativos, no domínio autêntico de nossa experiência imediata e prática da vida. (Dali, 1974)

Da mesma forma que todos sonham, somos todos, em maior ou menor grau, paranóicos. Para aqueles que vivem nas metrópoles, é melhor sê-los em maior grau já que a gramática da cidade, como queremos demonstrar neste artigo, está organizada de tal forma que o conjunto de significados obtidos através da atividade críticoparanóica é infinitamente maior e mais interessante do que aquele 
Trata-se do raciocínio que vimos nos exemplos dados acima e seu funcionamento não é tão misterioso como Reverdy nos faz crer. Neles podemos perceber que, apesar de a idéia da qual se parte estar, sob todos os aspectos, distante da idéia a qual se chega, somos obrigados a admitir que entre as imagens intermediárias (estejam elas visíveis ou não) há uma conexão clara de parte-todo, cäusa e efẹito e substituição (sinédoque, metonímia e metáfora), provocando, a cada passo, um pequeno deslocamento que, somados, são responsáveis pelo efeito insólito.

\section{Fluxo livre de idéias}

Apesar de Dalí opor o método crítico-paranóico ao flùxo livre de idéias, somos obrigados a reconhecer uma parte deste dentro da estrutura de seu método.

Este fluxo livre consiste em, em algum momento do processo de criação ou interpretação, suspender as faculdades críticas e de juízo, deixando fluir, livremente, a torrente do pensamento.

Durante algum tempo, o fluxo livre de idéias foi uma das principais, senão a principal técnica surrealista (e contra ela insurgiu-se Dalí). Dentre os frutos desta técnica estavam os textos de escrita automática e os poemas de fragmentos aleatórios apanhados ao acaso do jornal ou de qualquer outro lugar, como este trecho citado por Breton em seu manifesto:

numa fazenda isolada

dia a dia

agrava-se

o agradável

uma estrada de carruagens

leva-o à fímbria do desconhecido

(Breton, 2001)

Imaginemos, agora, quanta poesia desse tipo não há brotando da paisagem-colagem das cidades. De dentro de um automóvel 


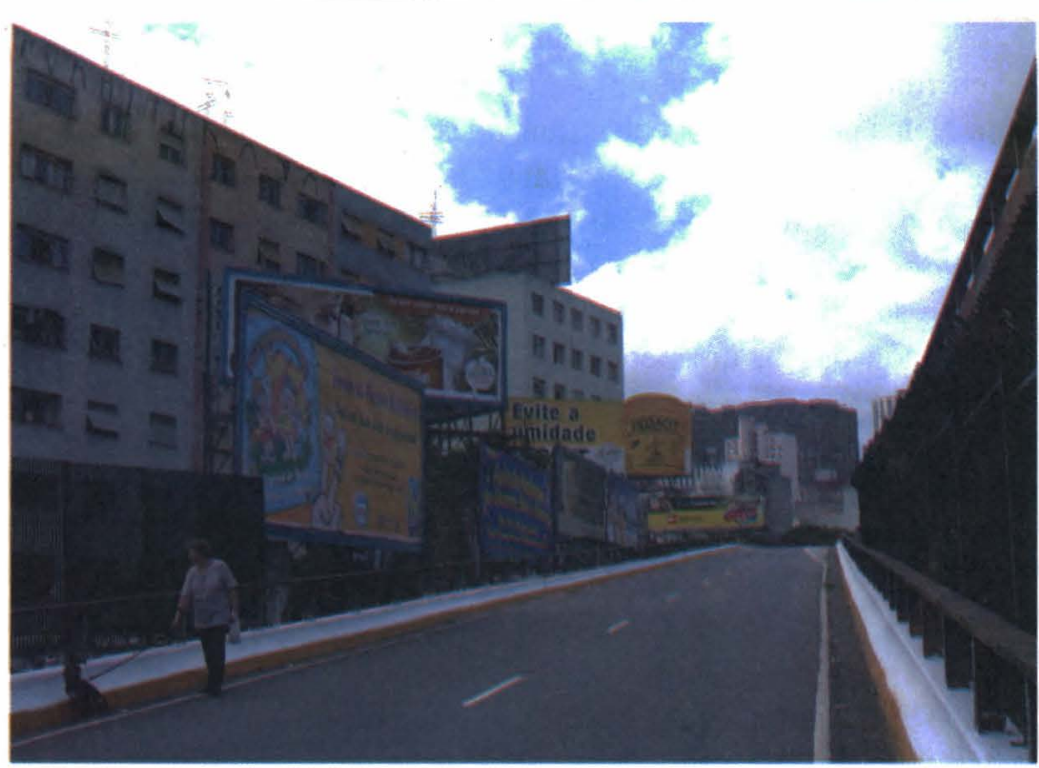

veloz uma frase lida pela metade junta-se a uma outra também pela metade formando sentenças que se encadeiam em parágrafos de um discurso insólito, estranho e belo. Como no exemplo a seguir:

Você vai ficar chá gelado

evite a umidade da gestante

faça consórcio

\section{O espaço da cidade}

O caos urbano manifesta-se também na forma de ocupação do espaço. Pontes, viadutos, postes, muros recortam a paisagem em pequenos fragmentos como num quebracabeças.

Estas molduras arquitetônicas variam o enquadramento conforme o deslocamento do sujeito neste espaço e, sob várias perspectivas, provocam amputações e sangramentos altamente 
significativos. É Breton quem primeiro chama a atenção para a possibilidade poética destes esquartejamentos:

Há um homem cortado em dois pela janela, mas não poderia haver ambigüidade, acompanhada como estava pela fraca representação visual de um homem andando, $e$ seccionado a meia altura por uma janela perpendicular ao eixo de seu corpo. Fora de dúvida era a simples aprumação de um homem debruçado à janela... (trecho de fragmento por citado por Peñuela, 1986)

Tendo esta frase em mente, Peñuela afirma:

a imagem surrealista, enquanto combinatória de signos, não se resume à união de duas realidades remotas: ela pode ser também, em termos de representação, a disjunção ou separação da integridade física de uma pessoa ou de uma coisa. (Peñuela, 1986, p. 94-95)

Assim, a cidade é inteiramente surrealista também nesse aspecto, senão vejamos.

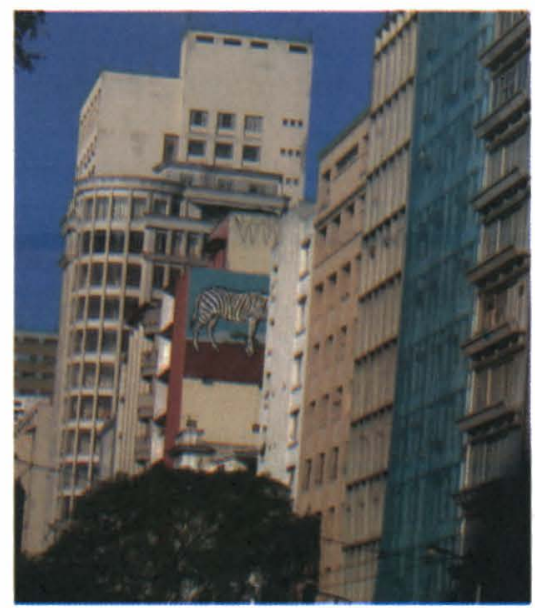

Um prédio-navalha decepa a zebra que de animal zôo-lógico vira mito-lógico. 


\section{Os materiais da cidade}

Como vimos, a cidade está construída com materiais originados das mais modernas tecnologias. Concreto, vidro, plástico, aço substituem a tinta e a tela na criação desta grandiosa obra surrealista.

\section{$O$ vidro e a imagem espectral}

O vidro não é, propriamente, um material moderno, pois já existe desde os primórdios da civilização. No entanto, nunca se usou tanto o vidro em construções quanto em nossa era.

O vidro comum, ao mesmo tempo em que deixa passar a luz e a imagem, também reflete parte desta luz e desta imagem. Na cidade brotam, por todos os lados, edifícios completamente revestidos com este material. Temos, então, um labirinto de espelhos - onde Narciso estaria definitivamente perdido - com prédios dispostos dos dois lados de ruas paralelas, criando uma perspectiva em abismo e visões terrificantes, como esta narrada por Guimarães Rosą:

Descuidado, avistei...

Explico-lhe: dois espelhos - um de parede, o outro de porta lateral, aberta em ângulo propício - faziam o jogo. E o que enxerguei, por instante, foi uma figura, perfil humano, desagradável ao derradeiro grau, repulsivo senão hediondo. Deu-me náusea, aquele homem, causava-me ódio e susto, eriçamento, espavor. E era - logo descobri... era eu, mesmo! O senhor acha que eu algum dia ia esquecer essa revelação? (Guimarães Rosa, 1991)

$\mathrm{E}$, de fato, nessa linda narrativa intitulada "O espelho", apồs essa revelação inicial, o narrador começa a procurar-se e descobrir-sè e, para isto, emprega os mais diversos modos de olhar-se no espelhd: "o rapidíssimo relatince; os golpes de esguelha a a longa obliquiidade apurada, as contra-surpresas, a finta de pálpebras, a tocaia com a luz de-repente acesa, os ângulos variados incessantemente. (...)visão 
parcialmente alheada (...): olhar não vendo. E, nas mudanças que dèscobre em seus reflexos e reflexões pergunta: "Você chegou a existir?"

Os reflexos da cidade - e todo o movimento surrealista parecem perguntar-nos o mesmo. A esta vida mesquinha e rasa, "vida digna de cães", podemos chamar existência?

As imagens deformadas pelos vidros-espelhos criam uma realidade alternativa que não segue as lógicas da Física nem da Geometria. Estas deformações provocam aquilo que Peñuela denomina ruptura por dupla ambigüidade, isto é, promove uma ruptura no nível da expressão e outra no nível do conteúdo, fazendo surgir novos significados comprometidos com desejos irracionais e insopitáveis. Assim, na imagem abaixo, mais de $50 \%$ do espaço está ocupado por uma outra cidade repleta de estruturas moles, tornando concreta a delirante previsão de Salvador Dali:

A 'mecânica', após um periodo de estupefaciente rigidez $e$ de funcionalismo falho, errado, conheceria todo o pegajoso, ignóminioso e sublime das secreções internas; aos rins flutuantes correspondem os motores flutuantes, os motorês moles, porque 'a época do mole', a época dos 'relógios moles', dos 'automóveis moles', das 'mesinhasde-cabeceira moles' (...) é a época que fora anunciada pelos 'médiuns' do Modern Style, criadores da célebre catedral mole que existe em Barcelona. As instalações de saliva central, percorrendo as curvas aerodinâmicas das eminentes casas moles, vaginais, curvas, ornamentais, imperialistas, recreativas, imaginativas, ansiosas, viciadas e surrealistas. Para trás a arquitetura de auto punição. Lugar ao aerodinamismo perverso, glandulário e de boa qualidade. (Dali, 1974, p. $62^{1}$

1 Em outro artigo de Dali, dedicado inteiramente ao assunto, intitulado " $\mathrm{Da}$ beleza terrificante e comestivel da Arquitetura Modern Style, o autor faz alusão "ao caráter nutritivo, comestível dessas espécies de casas, que não são outra coisa que as primeiras casas comestiveis, cuja existência verifica essa 'formação' urgente e tāo necessária para a imaginaçāo amorosa: poder comer na mais pura realidade o objeto do desejo. $(1974$, p. 127) 

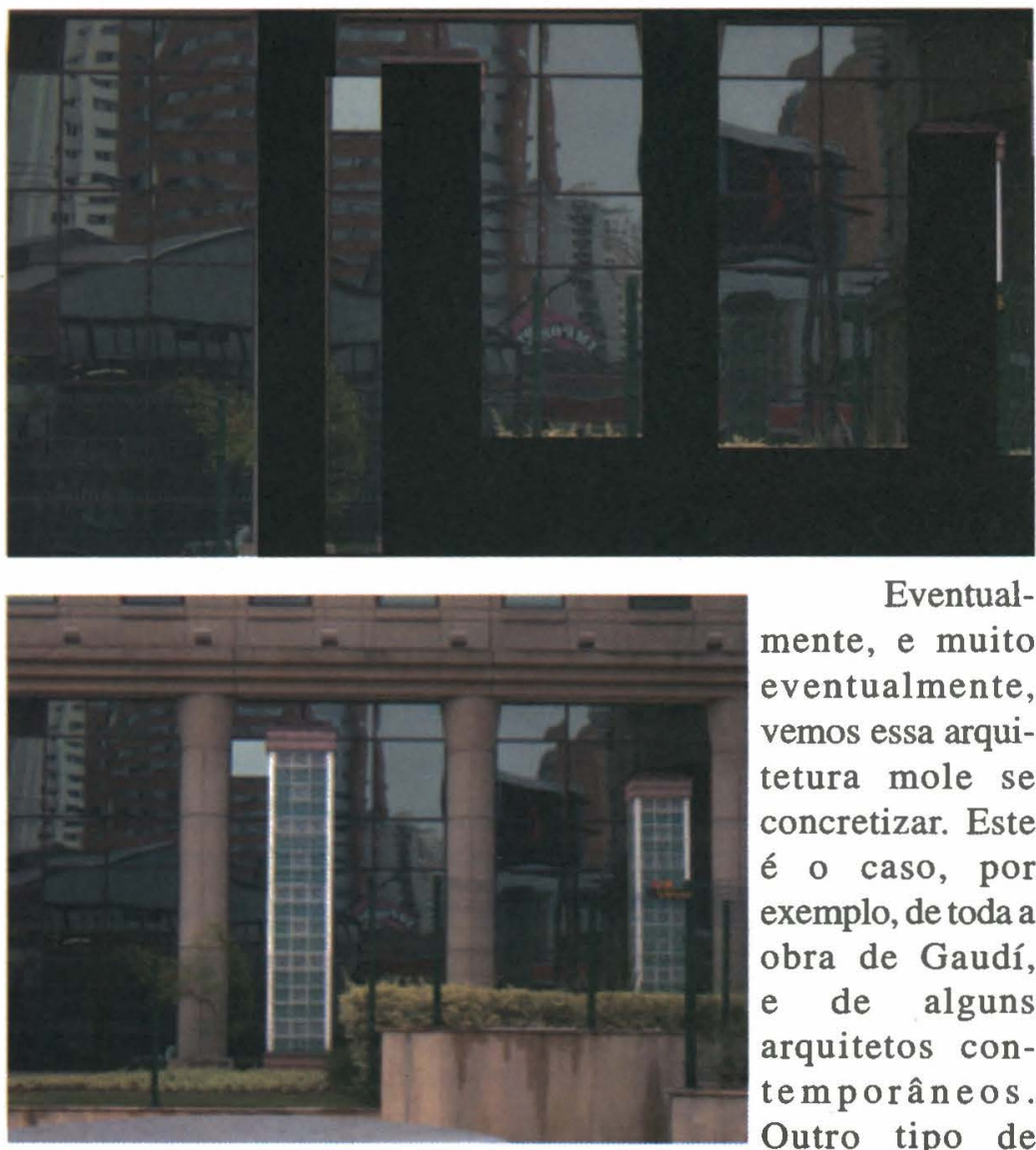

Eventualmente, e muito eventualmente, vemos essa arquitetura mole se concretizar. Este é o caso, por exemplo, de toda a obra de Gaudí, e de alguns arquitetos contem porâneos. Outro tipo de efeito muito apreciado pelos surrealistas é o da imagem-dupla - ou figuração dupla - que sugere múltiplas leituras a partir de uma única composição. Quem já não brincou, como faz Hamlet com Polônio, de inventar formas para as nuvens?
$H$ - Vedes aquela nuvem quase em forma de camelo?
$P$ - Pela santa missa, é mesmo como um camelo.
$H$ - Acho-a igual a uma doninha.
$P$ - Sim, tem o dorso de uma doninha.
$H$ - Ou de uma baleia?
$P$ - Muito semelhante ao de uma baleia. 


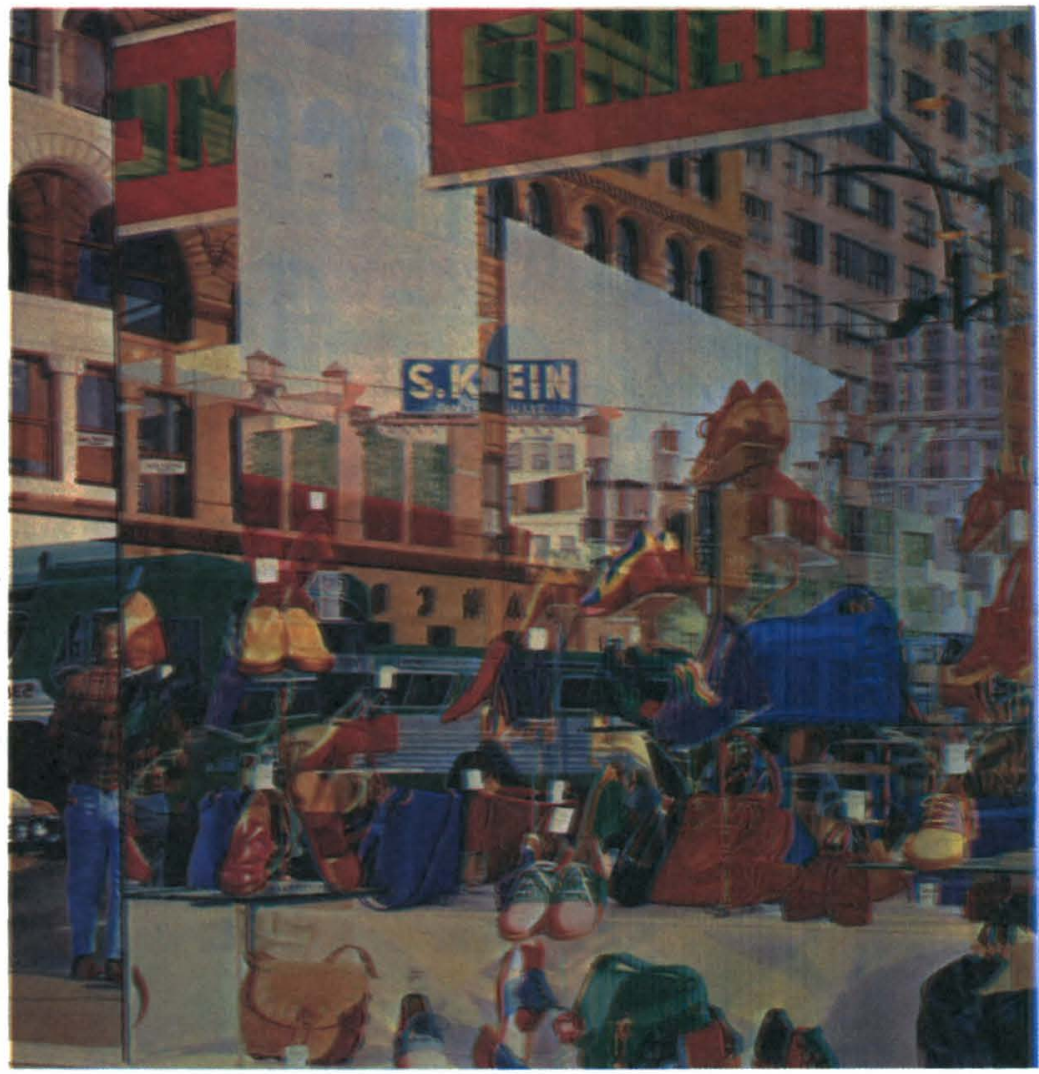

A transparência reflexiva do vidro é responsável pelo surgimento deste tipo de imagem dupla como ocorre nesta composição de Don Eddy intitulada "Sapatos novos para H."

Nesta imagem, o vidro, ao mesmo tempo em que reflete os edifícios e o movimento da rua com seus ônibus e pedestres, deixa transparecer também o interior da loja de sapatos criando uma nuvem colorida e sobreposta que, assim como faz Hamlet, pode servir às mais distintas leituras.

A diferença entre a imagem real da cidade com sua arquitetura opressiva e rígida e a imagem especular desta cidade é a mesma que existe entre o Fantasma e o Espectro. É Dali quem traça melhor estas diferenças: 
Fantasma - Simulacro do volume. Estabilidade obesa. Imobilidade ou mobilidade suspeita. Contornos efetivos. Perímetro metafísico. Chispas comestíveis. Prostração exibicionista. Tatilismo narcisista. Silhueta fenomenal. Angústia arquitetônica.

Espectro - Decomposição, destruição do volume ilusório. Instabilidade extrachata, extramagra. Rapidez luminosa. Contornos viscerais. Perímetro físico. Chispas minerais ou metálicas. Ereção exibicionista. Silhueta química. Dissecção explosiva. Instantaneidade tesa, histérica de vidente. Fino terror biológico. (Dali: 74 pg 47)

Novos materiais e o efeito do clima

$\mathrm{O}$ plástico teve, a partir da primeira metade do século $\mathrm{XX}$, um crescimento vertiginoso como jamais matéria-prima alguma experimentaraa e hoje tem servido às mais amplas aplicações na vida moderna. Interessa-me aqui, particularmente, aquelas aplicações em que o plástico adquire grande flexibilidade, servindo de suporte para imagens e mensagens. É o caso dos saquinhos de supermercado e das faixas publicitárias espalhadas por todos os lados.

A propriedade de amassar-se facilmente desperta uma atenção especial para estes objetos de uma inocência suspeita.

Na imagem abaixo, fica claro como um projeto gráfico criado para ser materializado em uma superfície plana, sofre alterações e rupturas, a partir do momento em que é veiculado em material flexível e exposto à ação do vento.

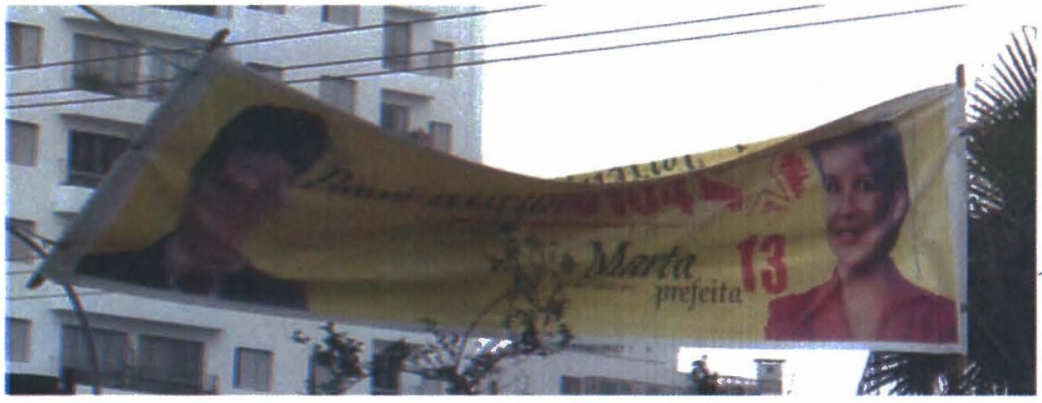

Significação $23 \cdot 108$ 
Os políticos desta faixa certamente prepararam-se horas para esta foto: roupas, maquiagem, ensaios de poses e sorrisos e, eventualmente, até cirurgia plástica. E tudo isto para, ao final, figurarem deformados ao estilo de caricaturas.

Sobre isso, é interessante conhecer a análise que faz Peñuela da bandeira nacional do Brasil, ao comparar como ela deve ser, segundo rígidos padrões geométricos e compositivos, propostos pelos órgãos governamentais, e como ela de fato é, ao se materializar em tecido e tremular ao vento. Ele então conclui:

Parece evidente, portanto, que o trabalho do desejo ou do vento - desmascara os sentidos óbvios da mensagem naquilo que eles têm de mais inócuo e, ao romper os arcabouços gráficos em que esses sentidos se acomodam, produz conteúdos em cujas formas se denuncia a participação irônica do inconsciente. (Peñuela: 1986,pg 68)

\section{Conclusão}

O mundo, para mim, já não é o mesmo! Uma vez li, não sei se de Dalí ou Breton, que uma vez surrealista, sempre surrealista.

Há coisas que, uma vez descobertas, alteram para sempre nossa forma de pénsar, ver e sentir. Tão certo quanto o fato de que olhamos muito e vemos pouco é o fato de que o não visto é não sentido, o não sentido é não vivido e, destarte, quem não vê, não vive.

Muitos poderão refutar as idéias aqui apresentadas - da mesma forma que o faz a escola funcionalista ao propor uma distinção entre a "semiótica da significação" e a "semiótica da comunicação", dảndo prioridade sempre a esta segunda - afirmando que os fenômenos apresentados não são intencionais e, assim sendo, não são válidos enquanto fenômeno significativo e poético. Quanto a isto, só me resta concordar com o que o Groupe $\mu$ diz a este respeito:

Se a sociedade nos oferece artefatos visuais cuja função é claramente a de significar (escultura, quadros 
abstratos, fotos, planos) esta função existe igualmente no caso de objetos tais como pôr do sol, árvores, pedras, solos, água. É necessário, e suficiente, que estes objetos sejam introduzidos por alguém, inclusive furtivamente, num processo de semiose qualquer; o qual, de certo modo, torna-se artificial: A noção de intenção se vê, de repente, substituida pela de projeção: projeção do receptor sobre uma série de fatos fisicos aos quais dá sentido. (esta é à teoria da leitura ativa, que sempre defendemos) (Groupe $\mu:$ 1933) (tradução de minha responsabilidade)

O surrealismo, movimento da primeira metade do século XX, nada mais feż do que trazer à tona outras lógicas de funcionamento do pensamento humano que já existiam antes do movimento e continuarão a existir para sempre propondo caminhos alternativos para superar os conceitos de que trata Edgar Morin:

idealizar (crer que a realidade pode reabsorver-se na idéia, que só o inteligivel é real); racionalizar (querer. encerrar a realidade na ordem e na coerência dum sistema, proibi-la de transbordar para fora do sistema, precisar justificar a existência do mundo conferindo-lhe um certificado de racionalidade); normalizar (isto é, eliminar o estranho, o irredutivel, o mistério) (trecho citado por Ana L. C. Moraes: 2001)

Como vimos, existem fortes traços de surrealismo em. Hamlet, assim como em Don Quixote, Hyeronimus Bosh, Archimboldo ou Guimarães Rosa, que afirma: Antes o absurdo que o óbvio, que o frouxo. Toda lógica contém boa dose de mistificação. Toda mistificação contém boa dose de inevitável verdade.

O absurdo; 0 êxtase e a simulação da loucura abrem as portas dos sentidos deixando entrar percepções de extrema força poética que enriquecem, e muito, esta nossa brisa de existência.

Finjamo-nos de loucos, pois! 


\section{Bibliografia}

BRETON, A. 2001. Manifestos do surrealismo. Rio de Janeiro: NAU Editora.

DALÍ, S. 1974. Sim ou a paranóia. Rio de Janeiro: Artenova.

FRUTIGER, A. 1997. Signos, símbolos, marcas, señales. Barcelona: Ediciones G. Gili.

GROUPE $\mu$, 1993. Tratado del signo visual. Madrid: Cátedra.

PEÑUELA C., E. 1986. Surrealismo, rupturas expressivas. São Paulo: Atual

GUIMARÃES ROSA, J. 1991. Primeiras Estórias . Rio de Janeiro: Nova Fronteira.

RUSSELL, B. 1947. História de la Filosofia Ocidental. Buenos Aires: Ed. Espasa

SHAKSPEARE, W. 1976. Hamlet. (Tradução de Péricles Eugênio da Silva Ramos) São Paulo: Abril Cultural. 